\title{
Ethylene and Structure-Function Relations of Xylella fastidiosa in Vitis vinifera in Pierce's Disease in Plants
}

\author{
E. Ann Ellis ${ }^{*}$ and B. Greg Cobb ${ }^{* *}$ \\ * Microscopy and Imaging Center, Texas A\&M University, College Station, TX 77843-2257 \\ **Department of Horticultural Sciences and Molecular and Environmental Plants Sciences, Texas A\&M \\ University, College Station, TX 77843-2133
}

Xylella fastidiosaa, a xylem-limited rickettsia-like microorganism, is responsible for Pierce's disease in grape vines and citrus chlorosis in citrus trees. The disease results in a slow, but significant water loss due to plugging of the xylem by tyloses and gums. Previously, it had been thought that the pathology is simply a result of physical plugging of the xylem by the bacteria. However, ethylene, a gaseous plant hormone, has been implicated in the etiology of Pierce's disease and other plant pathologies [1,2]. We examined the ultrastructural pathology of field grown, naturally infected and Ethiphon ${ }^{\circledR}$, precursor of ethylene, treated uninfected grape vines, Vitis vinifera, to verify a role for ethylene stimulation of tyloses and gums in the pathology of Pierce's disease by immunocytochemical localization of 1-aminocyclopropane-1-carboxylic acid oxidase (ACC oxidase), a biomarker for ethylene production.

Petioles of naturally infected $V$. vinifera were collected in the Texas A\&M vineyard and fixed for transmission electron microscopy (TEM) as previously described [3, 4]. Uninfected plants raised in the greenhouse were treated with Ethiphon ${ }^{\circledR}$, a precursor of ethylene, and then fixed for TEM. Thin sections were examined and the pathology was compared in both naturally infected and Ethiphon ${ }^{\circledR}$ treated plants. Sites of ACC oxidase were localized with goat anti-ACC oxidase (Santa Cruz Biotechnology, Santa Cruz, CA) followed by donkey anti-goat IgG secondary antibody labeled with $12 \mathrm{~nm}$ collodial gold (Jackson ImmunoResearch, West Grove, PA). Semi-quantitative data from colloidal gold counts were compared between the naturally infected, Ethiphon ${ }^{\circledR}$ treated uninfected and uninfected field grown plants.

ACC oxidase localized at low levels in uninfected petioles. There were tyloses in both naturally infected and Ethiphon ${ }^{\circledR}$ treated specimens and there was extensive localization of ACC oxidase as documented by colloidal gold immunocytochemistry (Figs. 1 and 2). Semi-quantitative analysis (Table 1) of the colloidal gold distribution indicated high levels of ethylene in the xylem of both naturally infected and in Ethiphon ${ }^{\circledR}$ treated uninfected petioles. Ethiphon ${ }^{\circledR}$ treated uninfected xylem had the highest levels of ACC oxidase $\left(56.5 \pm 3.28\right.$ gold particles $\left./ \mu \mathrm{m}^{2}\right)$ that were higher than the naturally infected xylem $(42.0 \pm 2.57,34.1 \pm 1.27$ gold particles $\left./ \mu \mathrm{m}^{2}\right)$ while uninfected xylem had much lower levels $\left(19.5 \pm 9.76\right.$ gold particles $\left./ \mu \mathrm{m}^{2}\right)$.

The immunocytochemical localization of ACC oxidase demonstrated the production of ethylene by the pathogen, $X$. fastidiosa, as well as by the host plant. Elevated levels of ethylene have been reported in a number of plant pathologies [2] and in the pathogens. In addition, ethylene is auto-catalytic and the production of ethylene by the pathogens can stimulate additional production of ethylene by the host plant as well. The evidence presented here indicates a role for increased production of tyloses and gums in response to increased ethylene production by both the pathogen, $X$. fastidiosa, and the host, $V$. vinifera. 
References

1. A. G. Perez-Donoso et al., Plant Physiology 143(2007) 1024.

2. W. F. Broekaert et al., Annu.Rev. Phytopathol. 44(2006) 393.

3. E. A. Ellis et al. Proc. Microsc. and Microanal. 14 suppl. 2(2008) 1554CD.

4. E. A. Ellis et al., Botany 88(2010) 596.

5. Supported by USDA UPHS Grant 05-0955 CA.
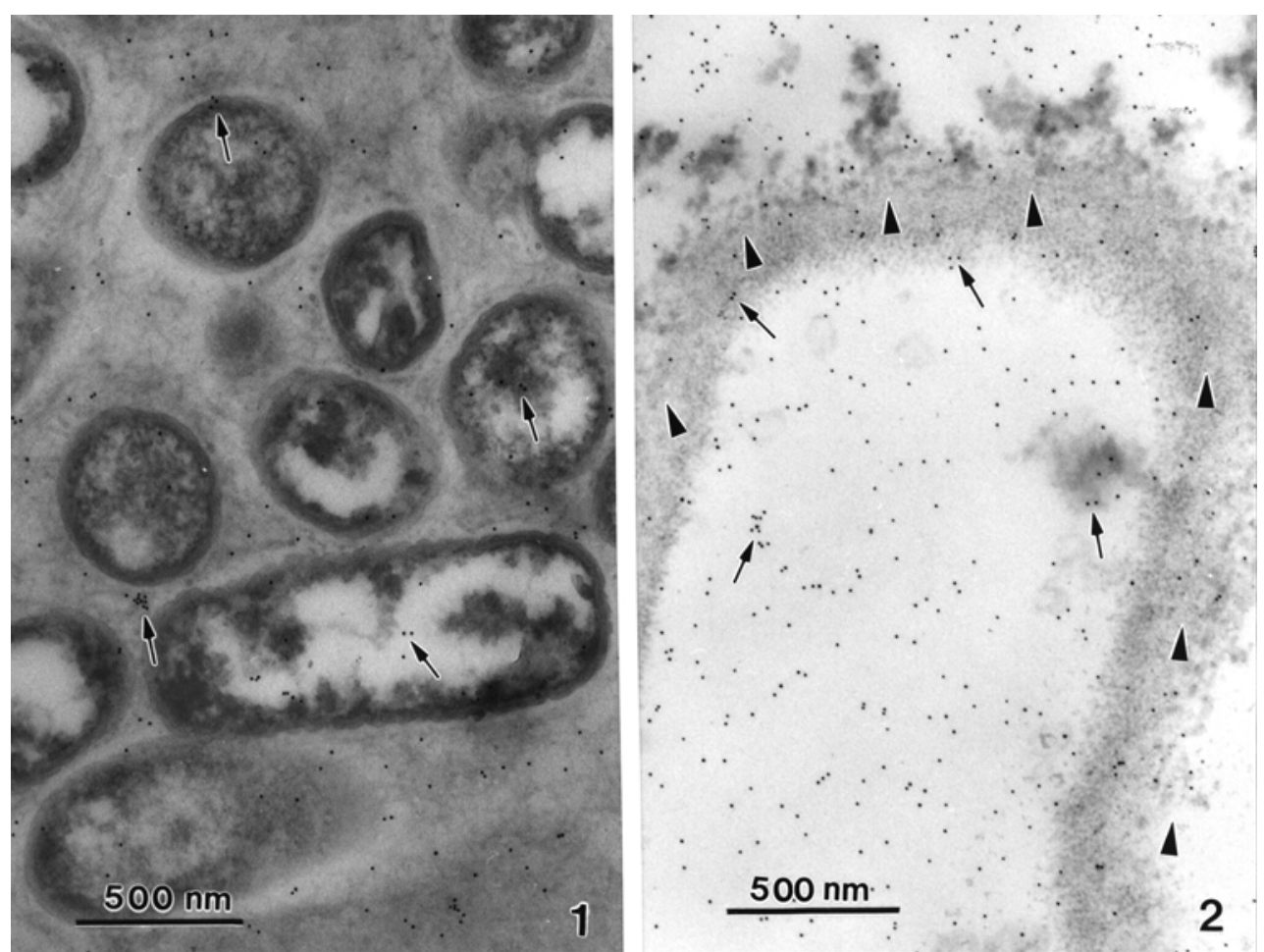

Fig. 1 Localization of ACC oxidase (arrows) by colloidal gold immunocytochemistry in xylem of naturally infected petiole.

Fig. 2 Localization of ACC oxidase (arrows) by colloidal gold immunocytochemistry in xylem of an uninfected, Ethiphon ${ }^{\circledR}$ treated petiole. Note the large tylose (arrowheads) in the uninfected xylem.

\begin{tabular}{|l|c|}
\hline \multicolumn{1}{|c|}{ TREATMENT } & Colloidal Gold Particles $/ \boldsymbol{\mu m}^{2}$ \\
\hline Ethiphon ${ }^{2}$ Treated Uninfected (Chardonnay) & $56.5 \pm 3.28$ \\
\hline Xylella Infected (LaRouge) & $34.1 \pm 1.27$ \\
\hline Xylella Infected (Sangiovese) & $42.0 \pm 2.57$ \\
\hline Uninfected, Untreated & $19.5 \pm 9.76$ \\
\hline
\end{tabular}

Table 1. Localization of ACC Oxidase in Xylem 